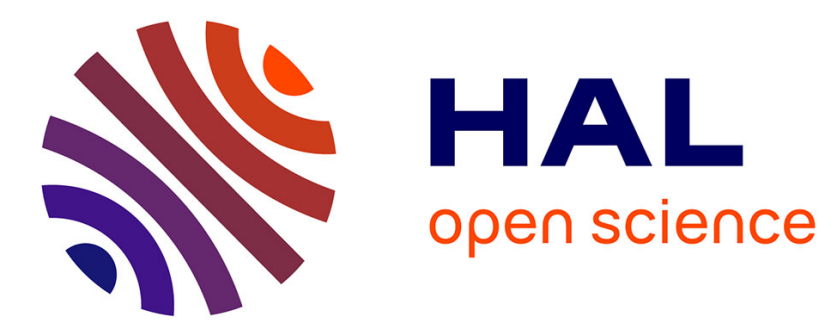

\title{
Photochemical C-H Silylation and Hydroxymethylation of Pyridines and Related Structures: Synthetic Scope and Mechanisms
}

Fatima Rammal, Di Gao, Sondes Boujnah, Aqeel Hussein, Jacques Lalevée, Annie-Claude Gaumont, Fabrice Morlet-Savary, Sami Lakhdar

\section{To cite this version:}

Fatima Rammal, Di Gao, Sondes Boujnah, Aqeel Hussein, Jacques Lalevée, et al.. Photochemical C-H Silylation and Hydroxymethylation of Pyridines and Related Structures: Synthetic Scope and Mechanisms. ACS Catalysis, 2020, pp.13710-13717. 10.1021/acscatal.0c03726 . hal-03011244

\author{
HAL Id: hal-03011244 \\ https://hal.science/hal-03011244
}

Submitted on 8 Dec 2020

HAL is a multi-disciplinary open access archive for the deposit and dissemination of scientific research documents, whether they are published or not. The documents may come from teaching and research institutions in France or abroad, or from public or private research centers.
L'archive ouverte pluridisciplinaire HAL, est destinée au dépôt et à la diffusion de documents scientifiques de niveau recherche, publiés ou non, émanant des établissements d'enseignement et de recherche français ou étrangers, des laboratoires publics ou privés. 


\section{Photochemical C-H- Silylation, and -}

\section{Hydroxymethylation of Pyridines and Related}

\section{Structures: Synthetic Scope and Mechanisms}

Fatima Rammal, ${ }^{\dagger}$ Di Gao, ${ }^{\dagger}$ Sondes Boujnah, ${ }^{\dagger}$ Aqeel A. Hussein, ${ }^{\ddagger}$ Jacques Lalevée, " AnnieClaude Gaumont, ${ }^{\dagger}$ Fabrice Morlet-Savary,"l and Sami Lakhdar ${ }^{*}$

† Normandie Univ., LCMT, ENSICAEN, UNICAEN, CNRS, 6, Boulevard Maréchal Juin, Caen 14000 France

‡ School of Chemistry, University of Southampton, Southampton, Hampshire, SO17 1BJ, United Kingdom

" Université de Haute-Alsace, CNRS, IS2M UMR 7361, F-68100 Mulhouse, France

$\S$ Université Paul Sabatier, Laboratoire Hétérochimie Fondamentale et Appliquée (LHFA, UMR 5069), 118 Route de Narbonne, 31062, Toulouse Cedex 09, France.

ABSTRACT: Considering the synthetic relevance of heteroarenes in various areas ranging from organic synthesis to medicinal chemistry, developing practically simple approaches to access functionalized heteroarenes is of significant value. Described herein is an efficient approach for $\mathrm{C}-\mathrm{H}$ silylation and hydroxymethylation of pyridines and related heterocycles by the 
combination of silanes or methanol with readily available $N$-methoxypyridinium ions with a low catalyst loading ( $2 \mathrm{~mol} \%$ ) under blue light irradiation. The synthetic importance of the developed reactions is illustrated by the synthesis of biologically relevant compounds. EPR spectroscopy, quantum yield measurements and DFT calculations allowed to understand reaction mechanisms of both photocatalytic reactions.

KEYWORDS: hydroxymethylation, mechanism, photoredox catalysis, pyridines, silylation.

\section{INTRODUCTION}

Heteroaromatic moieties are among the most widespread constituents of pharmaceutical compounds. Accordingly, the introduction of new functionalities through $\mathrm{C}-\mathrm{H}$ functionalization has attracted many interests during the last decades and resulted in the development of several elegant stoichiometric and catalytic strategies. ${ }^{1,2}$ Although transition metal catalyzed approaches are classically employed, the use of the well-known Minisci reaction remained one of the most useful technologies. ${ }^{3}$ This reaction has recently gained remarkable interest with the remarkable development of the significant development of photoredox catalysis ${ }^{4-10}$ that, in contrast to classical methods (stoichiometric silver oxidants at elevated temperatures), provided mild conditions for the formation of radicals. Naturally, many elegant photochemical Minisci-type reactions have been achieved and have been even more used for the synthesis of complex molecules. ${ }^{11-19,20-22}$ Less developed are $\mathrm{C}-\mathrm{H}$ silylation ${ }^{23-}$ 
28,29-32 and hydroxymethylation, which in spite of their unquestionable importance in organic synthesis, medicinal chemistry, and pharmacy (Figure 1), their access remained governed by transition metal catalysis.
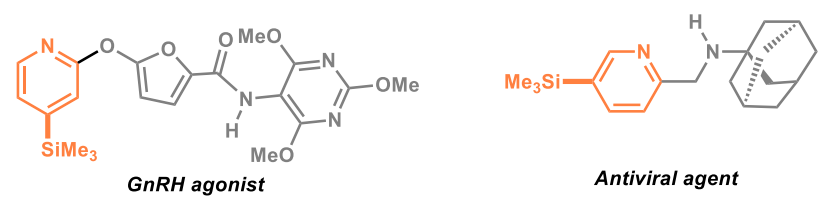

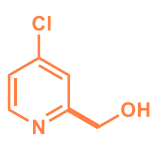

Inhibator of gastric acid secretion

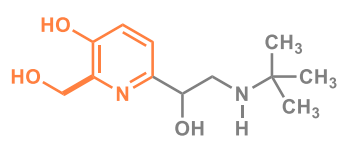

Pirbuterol

Figure 1. Representative biologically active silylated and hydroxymethylated compounds.

Because of the high nucleophilicity of silyl and hydroxyalkyl radicals, they are good candidates to react with electron-deficient heteroarenes rings. Unfortunately, the radical silylation is generally low yielding and requires harsh reaction conditions and stoichiometric amounts of oxidants. Additionally, they suffer from substantial amounts of double silylated products. ${ }^{33}$ Interestingly, some of these limitations have been overcome by Wang, Zhang and coworkers, ${ }^{34}$ who disclosed a visible light-mediated $\mathrm{C}-\mathrm{H}$ silylation of heteroarenes by employing trialkylhydrosilanes as silyl radical precursors (Scheme 1). However, the protocol still requires over stoichiometric amounts of peroxides and is restricted to five pyridine structures. Likewise, the radical C-H hydroxymethylation of heteroarenes has not been extensively developed since the seminal report by Minisci, ${ }^{35,36-38}$ where heterocyclic bases are combined with methanol and an oxidant (ammonium persulfate) under strong acidic conditions. ${ }^{35} \mathrm{~A}$ milder version of this photochemical process was recently disclosed by DiRocco, Krska and co-workers by using 
$\left[\operatorname{Ir}\left(\mathrm{dF}-\mathrm{CF}_{3}-\mathrm{ppy}\right)_{2}(\mathrm{dtbpy})\right] \mathrm{PF}_{6}$ as the photocatalyst an benzoyl peroxide $(\mathrm{PBO})$ as the terminal oxidant. ${ }^{39}$

Based on the dual reactivity of $N$-alkoxypyridinium ions (NAPs), ${ }^{40,41,42-45}$ as alkoxy radical precursors that are good hydrogen abstractors ${ }^{46,47,48}$ and as electrophilic partners in Minisci reactions, as previously reported by Hong and co-workers ${ }^{49-55,56}$ we hypothesized that NAPs should be good partner with silanes or methanol to accomplish photocatalytic $\mathrm{C}-\mathrm{H}$ silylation and hydroxymethylation, respectively (Scheme 1).

As shown in Scheme 1b, the oxygen-centered radical, formed upon single electron reduction of NPA by the excited state of the photocatalyst, abstracts a hydrogen atom from silanes ( $\mathrm{Si}-$ $\mathrm{H})$ or methanol $(\mathrm{C}-\mathrm{H})$ to generate the corresponding nucleophilic silyl and hydroxymethyl radicals. Those radicals can then interact with NPAs to yield after few subsequent steps the corresponding silylated and hydroxymethylated adducts. 
A Previous investigations
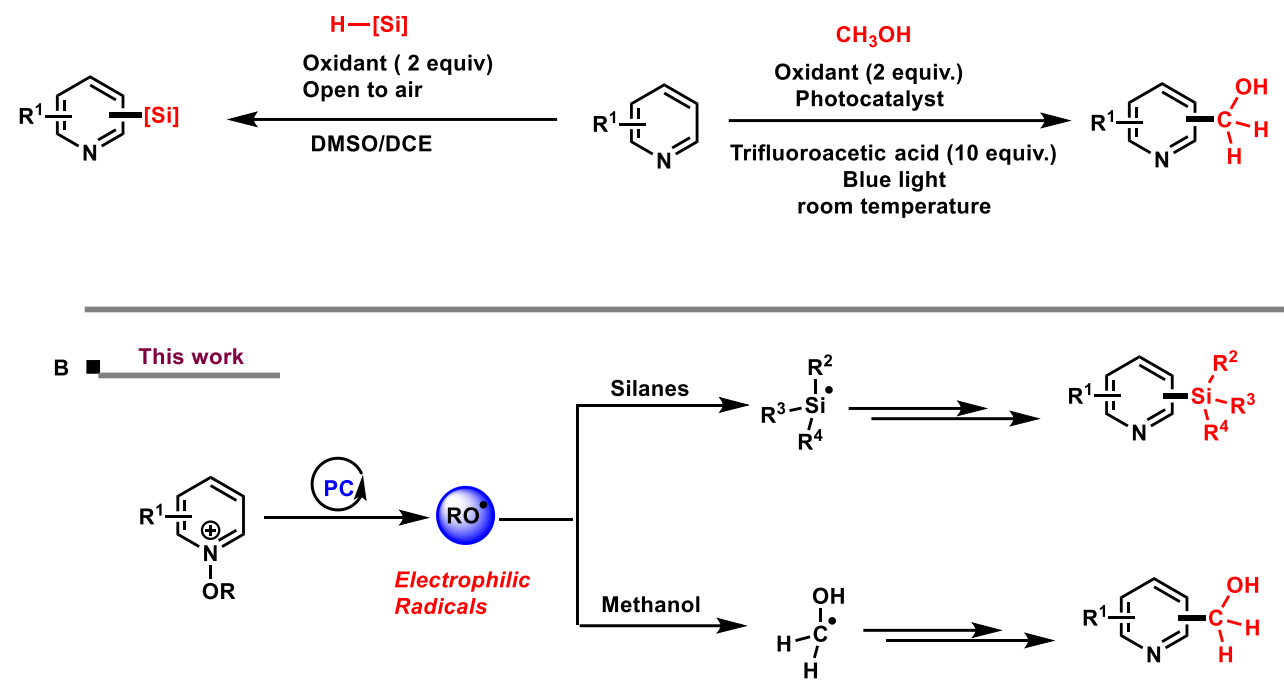

Scheme 1. Previous and current works for silylation and hydroxymethylation of heteroarenes.

\section{RESULTS AND DISCUSSIONS}

With the working hypothesis outlined above (Scheme 1), we studied the reaction of the pyridinium salt 1a with $t$-butyldimethylsilane ( $\left.{ }^{t} \mathrm{BuMe} 2 \mathrm{SiH}\right) 2 \mathrm{a}$ by investigating the effect of the 
photocatalyst, the base, and the solvent. Interestingly, and in contrast to previous studies, where excess of the silane is required, ${ }^{27}$ our optimization studies showed that only one equivalent of $2 \mathrm{a}$ with respect to two equivalents of $1 \mathrm{a}$ is optimal for the feasibility of the reaction. Under these conditions and by employing sodium bicarbonate as a base in $\mathrm{MeCN}$, the 3-phosphonated quinolinone (entry 3) and fac- $\operatorname{Ir}(\mathrm{ppy})_{3}$ (entry 4) gave 62 and $75 \%$ conversion, respectively. However, $\left[\mathrm{Ru}(\mathrm{bpy})_{3}\right]^{2+}$ or Eosin $\mathrm{Y}$ were found to be ineffective catalysts (Table 1, entries 1,2).

Keeping fac- $\operatorname{Ir}(\text { ppy) })_{3}$ as a photocatalyst, and $\mathrm{NaHCO}_{3}$ as a base, a solvent screening, including THF (entry 5, 8\%), DMF (entry 6, 3\%) and $\mathrm{CH}_{2} \mathrm{Cl}_{2}$ (entry 7, traces) was performed and showed disappointing results. Indeed, due to the low bond dissociation energy of $\mathrm{C}-\mathrm{H}$ bonds of THF and DMF, the $\alpha$-THF and carbamoyl radicals are predominantly formed and coupled with 1a to lead to the corresponding pyridines, which were detected by NMR spectroscopy as major products. Next, the effect of the base was evaluated and only $\mathrm{K}_{2} \mathrm{HPO}_{4}$ gave good conversion (entry 9,63\%), whereas very low or no reactions were observed with both inorganic (entries $8,10,11$ ) and organic bases (entry 12). Finally, the utility of the base, photocatalyst and light were ascertained as no reaction is possible in their absence (entries 13-15). 


\section{Table 1. Optimization and Initial studies of the Visible Light-Mediated Silylation. ${ }^{a}$}

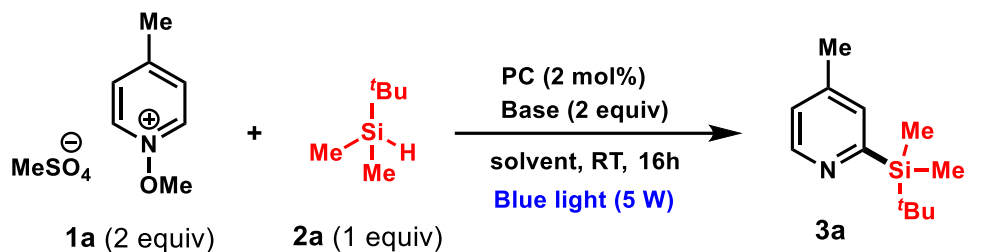

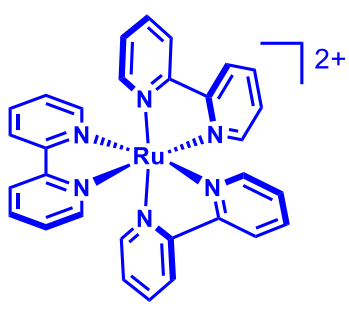

$\mathrm{Ru}(\mathrm{bpy})_{3}{ }^{2+}$<smiles>N#Cc1ccccc1-c1c2cc(Br)c(=O)c(Br)c-2oc2c(Br)c(O[N+](=O)[O-])c(Br)cc12</smiles>

Eosin $Y$

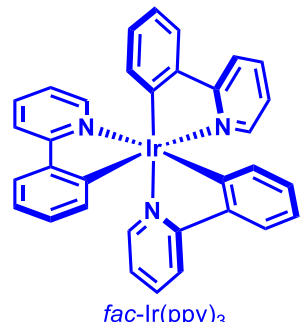<smiles>COc1ccc2c(c1)cc(P(=O)(c1ccccc1)c1ccccc1)c(=O)n2C</smiles>

Hong's photocatalyst

$\begin{array}{ccccc}\text { entry }^{a} & \text { Photocatalyst }(\mathbf{P C}) & \mathrm{Base} & \text { solvent } & \text { 3a, yield [\% }]^{b} \\ 1 & \mathrm{Ru}(\mathrm{bpy})_{3}{ }^{2+} & \mathrm{NaHCO}_{3} & \mathrm{MeCN} & \text { traces } \\ 2 & \text { Eosin Y } & \mathrm{NaHCO}_{3} & \mathrm{MeCN} & 0 \% \\ 3 & \mathrm{Hong} \text { 's PC } & \mathrm{NaHCO}_{3} & \mathrm{MeCN} & 62 \\ 4 & f a c-\operatorname{Ir}(\mathrm{ppy})_{3} & \mathrm{NaHCO}_{3} & \mathrm{MeCN} & 75 \\ 5 & f a c-\operatorname{Ir}(\mathrm{ppy})_{3} & \mathrm{NaHCO}_{3} & \mathrm{THF} & 8 \\ 6 & f a c-\operatorname{Ir}(\mathrm{ppy})_{3} & \mathrm{NaHCO}_{3} & \mathrm{DMF} & 3 \\ 7 & f a c-\operatorname{Ir}(\mathrm{ppy})_{3} & \mathrm{NaHCO}_{3} & \mathrm{DCM} & \text { Traces } \\ 8 & f a c-\operatorname{Ir}(\mathrm{ppy})_{3} & \mathrm{Na}_{2} \mathrm{CO}_{3} & \mathrm{MeCN} & 23 \\ 9 & f a c-\operatorname{Ir}(\mathrm{ppy})_{3} & \mathrm{~K}_{2} \mathrm{HPO}_{4} & \mathrm{MeCN} & 63 \\ 10 & f a c-\operatorname{Ir}(\mathrm{ppy})_{3} & \mathrm{~K}_{3} \mathrm{PO}_{4} & \mathrm{MeCN} & 24 \\ 11 & f a c-\operatorname{Ir}(\mathrm{ppy})_{3} & \mathrm{Cs}_{2} \mathrm{CO}_{3} & \mathrm{MeCN} & 6 \\ 12 & f a c-\operatorname{Ir}(\mathrm{ppy})_{3} & \mathrm{Et}_{3} \mathrm{~N}_{1} & \mathrm{MeCN} & 0 \\ 13 & - & \mathrm{NaHCO}_{3} & \mathrm{MeCN} & 0 \\ 14 & f a c-\operatorname{Ir}(\mathrm{ppy})_{3} & - & \mathrm{MeCN} & 9 \\ 15 & f a c-\operatorname{Ir}(\mathrm{ppy})_{3}{ }^{c} & \mathrm{NaHCO}_{3} & \mathrm{MeCN} & 0\end{array}$

$a$ Reactions were performed by reacting $N$-methoxypyridinium $1 \mathbf{a}(0.22 \mathrm{mmol}, 2$ equiv $)$ with $t$ butyldimethylsilane $\mathbf{2 a}(0.11 \mathrm{mmol}, 1$ equiv) in the indicated solvent $(4.4 \mathrm{~mL})$ using blue LEDs (5W) for 16 h. ${ }^{b}$ Yields were determined by ${ }^{1} \mathrm{H}$ NMR spectroscopy of the crude mixture in the presence of $1,1,2,2,-$ tetrachloroethane as internal standard. ${ }^{c}$ Reaction carried out in the absence of light. 
We next investigated the scope of the reaction (Figure 2). In this context, we first examined the reactivity of $N$-methoxypyridinium ions bearing para-substituted electron donating groups. Interestingly, the reaction proceeds well and the silylated adducts were isolated in fair yields (3a-3c; 55-65\%). Likewise, pyridines bearing electron-deficient groups such as phenyl (3d, 75\%) cyano (3e, 63\%), carbonyl (3f, 67\%) were obtained in good yields. However, the protocol works less efficiently with para-substituted trifluoromethyl group as $\mathbf{3} \mathbf{g}$ was isolated in $38 \%$ yield. The parent pyridine shows good reactivity ( $3 \mathrm{~h}, 74 \%$ ) and was obtained as an equimolar mixture of the two regioisomers. When 2-substituted pyridinium ions, bearing methoxy, cyano and chloro (1i-1k), were subjected to our optimized conditions, the C2 and C4 regioisomers were obtained (ratio $\approx 1: 1$ ) in good combined yields (47-97\%). Interestingly, each of these isomers was isolated by column chromatography and fully characterized (See Supporting Information). The compatibility of our conditions with chloro-substituted pyridine (3k) merits to be highlighted as it can lead to further synthetic transformations. Given the synthetic relevance of 2-aryl-silylated pyridines as precursors for the synthesis of ligands, we subsequently applied our approach to 2-arylated $N$-methoxypyridinium ions. Notably, the parent 2-phenyl (1m) and para-methyl aryl pyridinium ions (1n) delivered both silylated isomers in $79 \%$ and $80 \%$, respectively, whereas the para-methoxy and para-trifluoromethyl pyridinium ions (3o and 3p) gave both regioisomers along with the bis-silylated adducts.

Quinolines were also compatible with our conditions and 2- and 4-silylated quinolines (3q-3s) were obtained in fair yields (43 to 64\%). 


\section{Figure 2. Scope of the Photocatalytic Silylation of Heteroarenes. ${ }^{a}$}

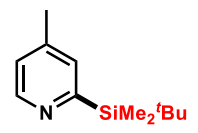

$3 a, 65 \%$

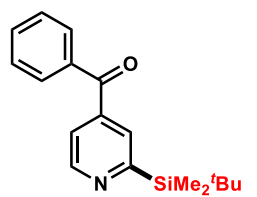

$3 f, 67 \%$

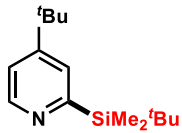

$3 b, 55 \%$

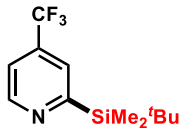

$3 \mathrm{~g}, 38 \%$

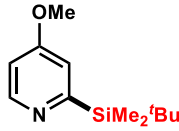

$3 c, 64 \%$

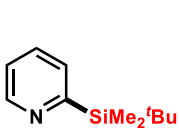

$3 h, 74 \%,(C 2: C 4=1: 1)$

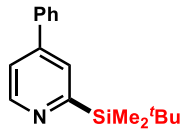

3d, $75 \%$<smiles>CCCCCCCCCCCCCCCCCCC</smiles>

$3 i, 65 \%,(C 2: C 4=1.3: 1)$

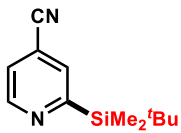

$3 e, 63 \%$

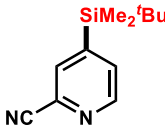

$3 \mathrm{j}, 47 \%,(\mathrm{C} 2: \mathrm{C} 4=1: 1.8)$

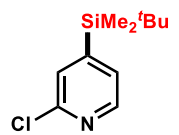<smiles>Cc1cc(SCC(C)(C)C)ccn1</smiles><smiles>CCCCCCCCCCCCCCCCCC</smiles>

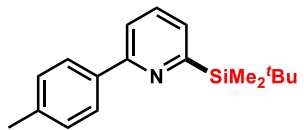

$3 k, 97 \%,(C 2: C 4=1.4: 1)$

$31,74 \%,(C 2: C 4: C 2, C 4=2.6: 5.6: 1)$

$3 m, 79 \%(C 2: C 4=2: 1)$

$3 n, 80 \%,(C 2: C 4=1.5: 1)$<smiles>CCCCCc1cccc(-c2ccc(OC)cc2)n1</smiles>

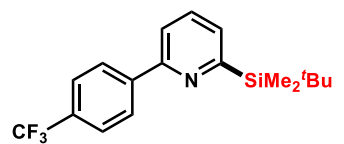

$\mathrm{MeO}$<smiles>CCCCCCCCCCOc1ccc2nc(OCCCC)ccc2c1</smiles><smiles>CCCCSc1cc(C)c2ccccc2n1</smiles>

3o, 35\% (C2:C4:C2,C4 = 1:5:1)

$3 p, 54,(C 2: C 4: C 2, C 4=3.6: 1: 1.4)$

$3 q, 64 \%$

$3 r, 43 \%$

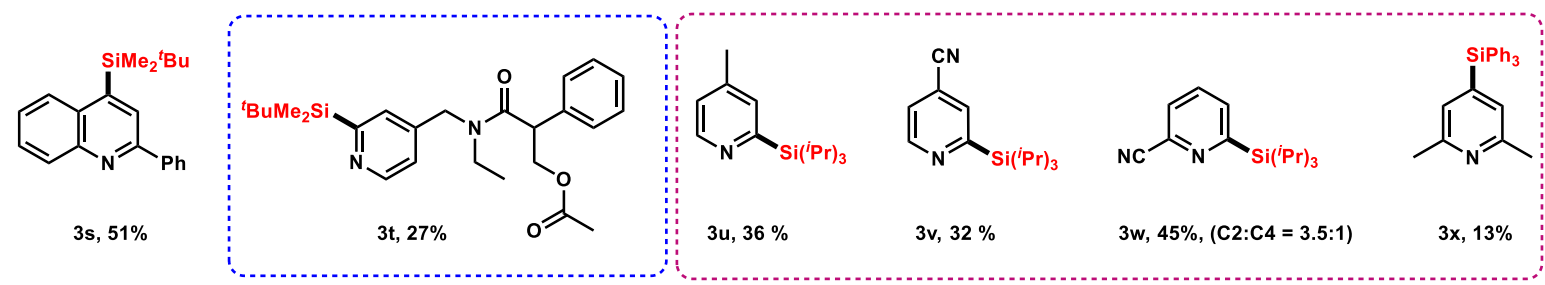

${ }^{a}$ Standard conditions: $N$-alkoxypyridinium 1 (2 equiv) was combined with 2 a (1 equiv) in the presence of $f a c$ - $\operatorname{Ir}(\mathrm{ppy})_{3}$ ( 2 mol\%) and $\mathrm{NaHCO}_{3}$ (2 equiv) in $\mathrm{CH}_{3} \mathrm{CN}(0.05 \mathrm{M})$ using blue LEDs (5W) for $16 \mathrm{~h}$. 
Importantly, this protocol was applied for the synthesis of the biorelevant target $3 \mathrm{t}$, which was obtained in comparable overall yield to that obtained by Zhang et al. ${ }^{18}$ The chloro, cyano, and ester functional groups, remained intact, thus allowing for further chemical transformations. Finally, the reactions of other silanes with pyridinium ions 1 were also tested and gave low to modest yields ( $3 \mathbf{u}-3 \mathbf{x}, 13-45 \%)$.

As outlined above, considering the omnipresence of methylol functional group in a large variety of biologically active compounds and natural products, we examined our photocatalytic approach combining $N$-methoxypyridinium ions with methanol to synthesize hydroxymethylated pyridines (Figure 3). It should be noted that Lei et al..$^{57}$ reported a practically simple hydroxymethylation of a large variety of quinolines and isoquinolines in the presence of substoichiometric amounts of Selectfluor ${ }^{\circledR}{ }^{41}$ Unfortunately, pyridines were found to be unreactive under their optimized conditions, thus, calling for an alternative approach which would be complementary to Lei's method. With this in mind, we reacted methanol (4) with different $N$-methoxypyridinium ions (1) under the optimized conditions described above (Figure 2). Pleasingly, the desired adducts were obtained in good yields.

As shown in Figure 3, 4-substituted pyridinium ions delivered the alcohols (5a-5e) in 42 to $82 \%$ yields as single isomers. Noteworthily mentioning, the (4-chloro-2pyridinyl)methanol $\mathbf{5 f}$, which is known as inhibitor of gastric acid secretion (Figure 1), was isolated in $66 \%$ yield. 
As for the $\mathrm{C}-\mathrm{H}$ silylation reaction, two regioisomers, in almost 1:1 ratio, were obtained (5g-51, 62-99\% combined yields) when the unsubstituted, as well as 2-substituted pyridinium salts, were employed. A $41 \%$ yield has been obtained with 3,5dimethylpyridinium ion (5m) and the process works well with quinolinium (5n, 5o).

Figure 3. Scope of the Photocatalytic Hydroxymethylation of Heteroarenes. ${ }^{a}$

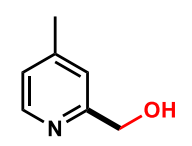

$5 a, 82 \%$
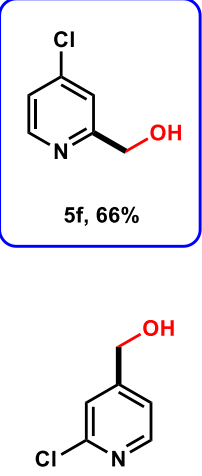

$5 \mathrm{k} 71 \%$ (C2:C4 = 1:1)

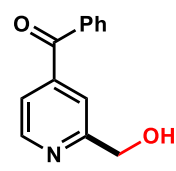

$5 b, 82 \%$

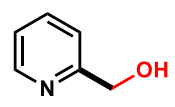

$5 \mathrm{~g}, 88 \%$ (C2:C4 = 3:2)<smiles>OCc1ccnc(Br)c1</smiles>

$51,62 \%$

(C2:C4 = 1:1)

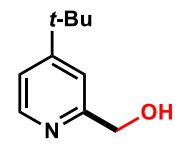

5c, $42 \%$<smiles>OCc1cccc(-c2ccccc2)n1</smiles>

$5 \mathrm{~h}, 99 \%$
(C2:C4 = 1:1

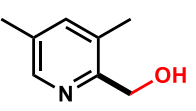

$5 \mathrm{~m}, 41 \%$<smiles>OCc1cc(-c2ccccc2)ccn1</smiles>

5d, $43 \%$<smiles>Cc1cccc(CO)n1</smiles>

$5 i, 90 \%$
$(C 2: C 4=3$

$(\mathrm{C} 2: \mathrm{C} 4=3: 2)$

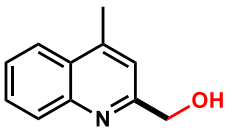

5n, $59 \%$

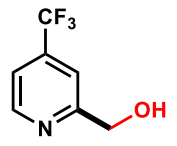

5 e, $65 \%$<smiles>OCc1ccnc(Cc2ccccc2)c1</smiles>

$5 j, 73 \%$
(C2:C4 = 1:

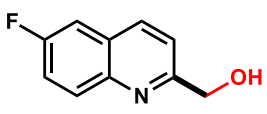

$50,77 \%$
(C2:C4 = $7: 3)$ 
${ }^{a}$ Reaction conditions: $N$-alkoxypyridinium 1 (1 equiv) $\mathrm{MeOH}$ (5 equiv), fac-Ir(ppy)3 (2 mol\%), $\mathrm{NaHCO}_{3}$ (1 equiv) were reacted in $\mathrm{CH}_{3} \mathrm{CN}(0.05 \mathrm{M})$ under blue light irradiation (LEDs, $5 \mathrm{~W})$ for $2 \mathrm{~h}$.

\section{Mechanistic Investigations}

To gain more insights about mechanisms of the two photocatalytic processes, a luminescence-quenching study was performed. The Stern-Volmer fluorescence experiment showed that the excited state of $f a c-\operatorname{Ir}(\mathrm{ppy}){ }^{*}$ is quenched by the pyridinium salt $1 \mathrm{a}$, and a linear relationship between the quenching efficiency and the concentration of 1a was obtained (Figure S5, Supporting Information). This indicates the ability of the photocatalyst in its excited form $\left[\text { fac- } \operatorname{Ir}(\text { ppy })_{3}\right]^{*}$ to activate the $\mathrm{N}-\mathrm{O}$ bond of $1 \mathrm{a}$.

We next characterized the key radical intermediates involved in each photoreaction by spintrapping electron paramagnetic resonance spectroscopy. In this context, the combination of fac-Ir(ppy) 3 with 4 -methyl $N$-methoxypyridinium ion in the presence of $N$-tert-butyl- $\alpha$ phenylnitrone $(\mathrm{PBN})$ as a spin trap and irradiated under blue light illumination $\left(\lambda_{\max }=420 \mathrm{~nm}\right)$ showed a triplet of doublets $(\mathrm{a}=13.6 \mathrm{G}$; $\mathrm{aH}=1.8 \mathrm{G})$, that is characteristic of MeO-PBN adduct (Figure 4)..$^{58,59}$

In accordance with our DFT calculations (Figure 5) that revealed viable hydrogen atom transfer reactions between $(\cdot \mathrm{OMe})$ and silane $\left(2 \mathrm{a} ; \Delta \mathrm{G}^{*}=12.1 \mathrm{kcal} / \mathrm{mol}\right)$ or methanol $\left(4 ; \Delta \mathrm{G}^{*}=\right.$ 
$14.5 \mathrm{kcal} / \mathrm{mol}$ ), the formation of the silyl and hydroxymethyl radicals was confirmed by EPR spectroscopy. Indeed, the irradiation of a mixture of fac-Ir(ppy)3, 4-methyl $N$ methoxypyridinium ion with methanol in the presence of PBN gave rise to a signal that consists of a triplet of doublets $(\mathrm{aN}=13.9 \mathrm{G}$, aн $=2.1 \mathrm{G}$ ), which could be attributed to the trapping of the hydroxymethyl-PBN radical (Figure 4), in agreement with previous results reported by Durand. ${ }^{60}$ When the same EPR experiment was carried out with silane 2a instead of methanol, the methoxyl-PBN radical was detected along with a new radical species $(\mathrm{a}=$ 15.0 $\mathrm{G}, \mathrm{aH}=4.3$ ) that could be assigned as the silyl-PBN radical (See supporting information). ${ }^{61}$<smiles>CCN(OC)C(OC)c1ccccc1</smiles>
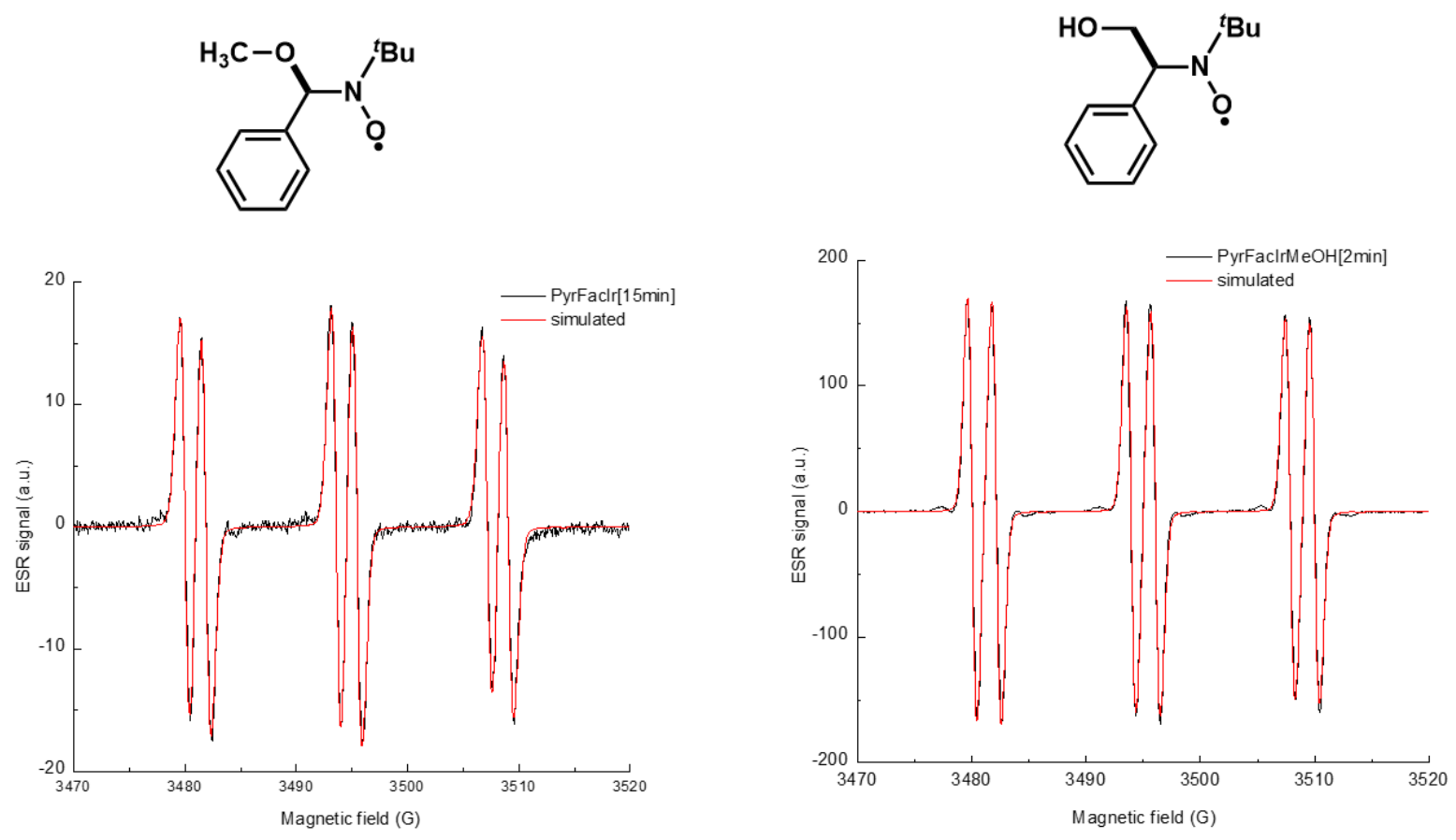

Figure 4. EPR experiments for the trapping of the methoxyl and the hydroxymethyl radicals with $N$-tert-butyl- $\alpha$-phenylnitrone (PBN). 
The addition of the highly nucleophilic silyl radical $\left(\omega^{-}=0.75\right.$, for more details, see supporting information) at the $\mathrm{C} 4$ position of the pyridine ring proceeds with an activation energy of 7.1 $\mathrm{kcal} / \mathrm{mol}$ to give the radical species 6 . Not surprisingly, the reaction of the less nucleophilic hydroxomethyl $\left(\omega^{-}=0.66\right)$ radical at the $\mathrm{C} 4$ position is $2.2 \mathrm{kcal} / \mathrm{mol}$ slower than the silyl addition. The weak difference in energy between the addition of radicals at the C2 and C4 positions $(0.2-0.6 \mathrm{kcal} / \mathrm{mol})$ may account for the low experimental regioselectivity (Figures 2 \& 3). Both pathways, silylation and hydroxymethylation, undergo a low barrier deprotonation to form the radical species 7, which upon $\mathrm{N}-\mathrm{O}$ bond homolysis, yield the desired product and generate a methoxy radical to persist a new radical chain pathway. This hypothesis is supported by the high reaction quantum yields of $\phi=10$ for silylation, and $\phi=21.2$ for hydroxymethylation (For details, see the supporting information).

It should be pointed out at this stage that one important factor for the feasibility of the Minisci reactions with $N$-alkoxypyridinium ions (NAPs) is the resistibility of the nucleophilic radical towards single-electron oxidation. In fact, in a series of seminal contributions, Farid and coworkers elucidated, through in-depth physical organic investigations, ${ }^{62-64}$ the ability of NPAs to oxidize alcohols into the corresponding carbonyl compounds under photocatalytic conditions. It has been demonstrated that energetic limitations of these chain propagations depend on the reduction potential of the pyridinium salts and the oxidation potential of the $\alpha$-hydroxy radicals. It appears from our studies on silylation and hydroxymethylation as well as from previous work reported by the Hong group on alkylation, acylation and phosphorylation of heteroarenes, ${ }^{55}$ that the addition of the nucleophilic radicals into NPAs are irreversible and faster than the oxidation of 
the radicals $\left(\mathrm{X}^{\bullet}\right)$ to form the corresponding cations $\left(\mathrm{X}^{+}\right)$(Figure 4$)$. Based on this hypothesis, the low yields of the silylated pyridines $\mathbf{3} \mathbf{u}-\mathbf{3} \mathbf{x}$ can be attributed to the oxidation of the silyl radicals. To confirm this, we analyzed by NMR spectroscopy the silylation of para-methyl $N$ alkoxypyridinium ion with triphenylsilane under the optimized conditions and detected the formation of the methoxyltriphenylsilane in good yield (See supporting information). This adduct is formed upon addition of methanol, formed after HAT of the methoxy radical with the triphenylsilyl cation (Figure 5). 


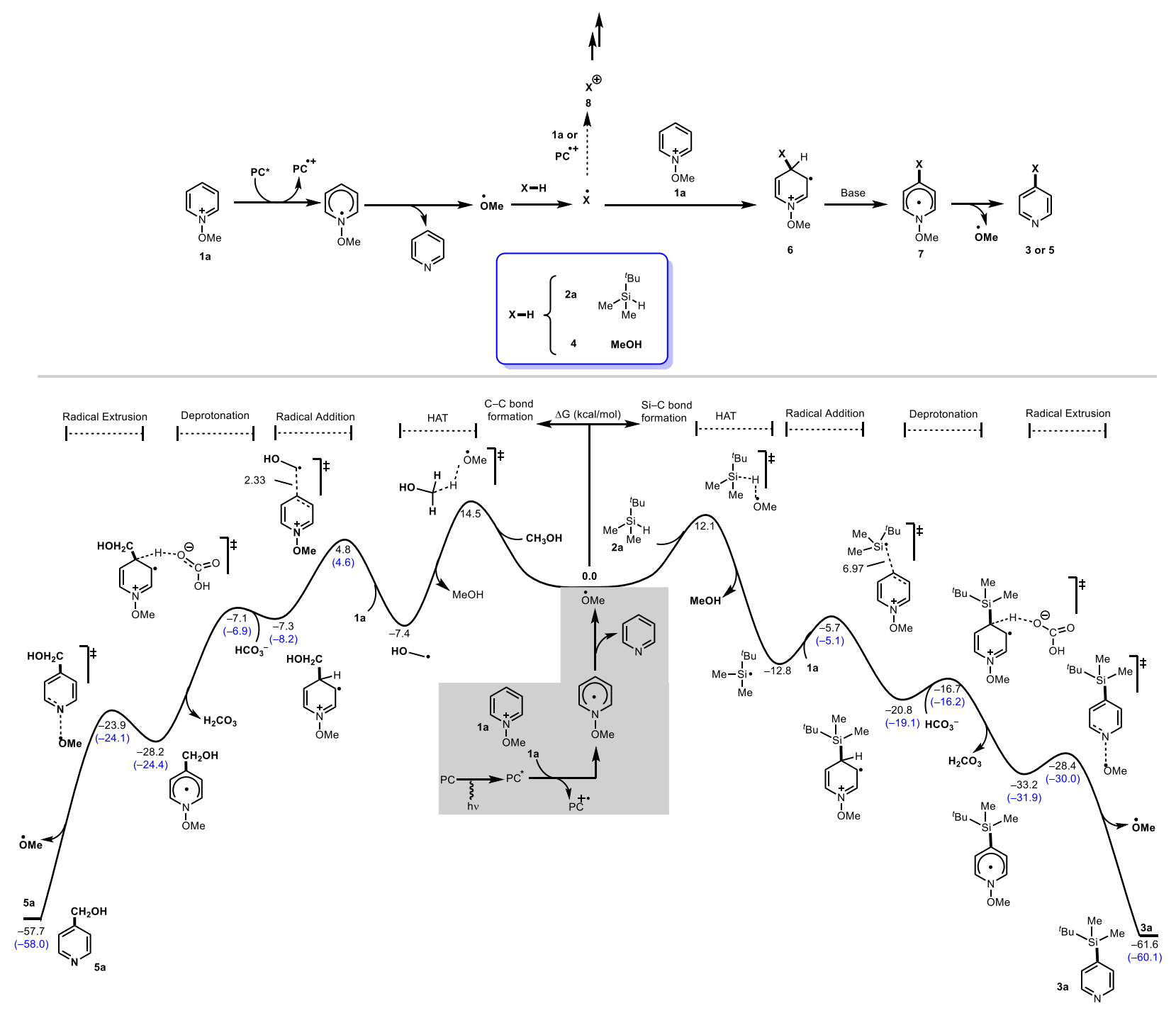

Figure 5. Free energy profile for the photocatalytic silylation and hydroxymethylation, calculated at the SMD-(ACN)-M06-2X/def2-TZVP//B3LYP/6-31+G(d) level of theory. Energies for the C2regioisomer are given between brackets. For computational details, see supporting information. 


\section{Conclusion}

The silylation and hydroxymethylation of heteroarenes are very important reactions in various areas ranging from catalysis to medicinal chemistry. While Minisci-type versions of those reactions have been developed, they required the use of external oxidants and Bronsted acids to activate the heteroarenes. Taking advantage of the dual reactivity of NPAs as hydrogen atom abstractors under photoredox conditions and as electrophiles, we demonstrate herein the ability of those salts to promote $\mathrm{C}-\mathrm{H}$ silylation and hydroxymethylation. Importantly, the scope of both reactions is wide, tolerate many functionalities and has further been explored for the synthesis of biologically relevant products. A combination of EPR spectroscopy and DFT allowed to characterize silyl and hydroxymethyl radicals and even more to understand factors controlling both photoreactions. These practically simple and mild transformations are likely to be useful for synthesizing privileged organic scaffolds.

\section{ASSOCIATED CONTENT}

General experimental procedures and analytic data of new compounds $\left({ }^{1} \mathrm{H},{ }^{13} \mathrm{C}\right.$, and ${ }^{19} \mathrm{~F}$ NMR spectra), EPR experiments, and DFT calculations.

\section{AUTHOR INFORMATION}

\section{Corresponding Author}

Sami Lakhdar, CNRS, Université Toulouse III, Paul Sabatier, Laboratoire d'Hétérochimie

Fondamentale et Appliquée, LHFA UMR 5069, 31062 Toulouse, France 
lakhdar@chimie.ups-tlse.fr

\section{Author Contributions}

F.R, D.G and S.B performed the photocatalytic reactions, characterized the final products, and measured quantum yields. A. A. H. carried out the DFT calculations and F.M.S. conducted EPR experiments. S.L designed the project and wrote the manuscript.

\section{ACKNOWLEDGMENT}

The authors thank the Centre National de la Recherche Scientifique, Labex Synorg (ANR-11LABX-0029), and Normandie Université for financial support. F. R. is grateful to the French Ministry of Research for a doctoral scholarship. The authors acknowledge the University of Southampton for the computational resources (iridis4 supercomputers).

\section{DEDICATIONS}

This paper is dedicated in memory of our friend and colleague François Couty (Institut Lavoisier Versailles).

\section{REFERENCES}

(1) Vitaku, E.; Smith, D. T.; Njardarson, J. T. Analysis of the Structural Diversity, Substitution Patterns, and Frequency of Nitrogen Heterocycles among U.S. FDA Approved Pharmaceuticals. J. Med. Chem. 2014, 57 (24), 10257-10274. https://doi.org/10.1021/jm501100b. 
(2) Baumann, M.; Baxendale, I. R. An Overview of the Synthetic Routes to the Best Selling Drugs Containing 6-Membered Heterocycles. Beilstein J. Org. Chem. 2013, 9, 22652319. https://doi.org/10.3762/bjoc.9.265.

(3) Proctor, R. S. J.; Phipps, R. J. Recent Advances in Minisci-Type Reactions. Angew. Chemie - Int. Ed. 2019, 58 (39), 13666-13699. https://doi.org/10.1002/anie.201900977.

(4) Prier, C. K.; Rankic, D. A.; MacMillan, D. W. C. Visible Light Photoredox Catalysis with Transition Metal Complexes: Applications in Organic Synthesis. Chem. Rev. 2013, 113 (7), 5322-5363. https://doi.org/10.1021/cr300503r.

(5) Wimmer, A.; König, B. Photocatalytic Formation of Carbon-Sulfur Bonds. Beilstein J. Org. Chem. 2017, 14 (Scheme 1), 54-83. https://doi.org/10.3762/bjoc.14.4.

(6) Narayanam, J. M. R.; Stephenson, C. R. J. Visible Light Photoredox Catalysis: Applications in Organic Synthesis. Chem. Soc. Rev. 2011, 40 (1), 102-113. https://doi.org/10.1039/b913880n.

(7) Marzo, L.; Pagire, S. K.; Reiser, O.; König, B. Visible-Light Photocatalysis: Does It Make a Difference in Organic Synthesis? Angew. Chemie - Int. Ed. 2018, 57 (32), 1003410072. https://doi.org/10.1002/anie.201709766.

(8) Xuan, J.; Xiao, W. J. Visible-Light Photoredox Catalysis. Angew. Chemie - Int. Ed. 2012, 51 (28), 6828-6838. https://doi.org/10.1002/anie.201200223. 
(9) Yoon, T. P.; Ischay, M. A.; Du, J. Visible Light Photocatalysis as a Greener Approach to Photochemical Synthesis. Nat. Chem. 2010, 2 (7), 527-532. https://doi.org/10.1038/nchem.687.

(10) Romero, N. A.; Nicewicz, D. A. Organic Photoredox Catalysis. Chem. Rev. 2016, 116 (17), 10075-10166. https://doi.org/10.1021/acs.chemrev.6b00057.

(11) Jatoi, A. H.; Pawar, G. G.; Robert, F.; Landais, Y. Visible-Light Mediated Carbamoyl Radical Addition to Heteroarenes. Chem. Commun. 2019, 55 (4), 466-469. https://doi.org/10.1039/c8cc08326f.

(12) DiRocco, D. A.; Dykstra, K.; Krska, S.; Vachal, P.; Conway, D. V.; Tudge, M. Late-Stage Functionalization of Biologically Active Heterocycles through Photoredox Catalysis. Angew. Chemie - Int. Ed. 2014, $53 \quad$ (19), 4802-4806. https://doi.org/10.1002/anie.201402023.

(13) Dondi, D.; Fagnoni, M.; Molinari, A.; Maldotti, A.; Albini, A. Polyoxotungstate Photoinduced Alkylation of Electrophilic Alkenes by Cycloalkanes. Chem. - A Eur. J. 2004, 10(1), 142-148. https://doi.org/10.1002/chem.200305285.

(14) Giedyk, M.; Santos, M.; Cybularczyk-Cecotka, M.; König, B. Minisci C-H Alkylation of Heteroarenes Enabled by Dual Photoredox/Bromide Catalysis in Micellar Solutions. Chem. - A Eur. J. 2020. https://doi.org/10.1002/chem.202002320. 
(15) Klauck, F. J. R.; James, M. J.; Glorius, F. Deaminative Strategy for the Visible-LightMediated Generation of Alkyl Radicals. Angew. Chemie - Int. Ed. 2017, 56 (40), 1233612339. https://doi.org/10.1002/anie.201706896.

(16) Li, G. X.; Hu, X.; He, G.; Chen, G. Photoredox-Mediated Minisci-Type Alkylation of NHeteroarenes with Alkanes with High Methylene Selectivity. ACS Catal. 2018, 8 (12), 11847-11853. https://doi.org/10.1021/acscatal.8b04079.

(17) Gutiérrez-Bonet, Á.; Remeur, C.; Matsui, J. K.; Molander, G. A. Late-Stage C-H Alkylation of Heterocycles and 1,4-Quinones via Oxidative Homolysis of 1,4Dihydropyridines. J. Am. Chem. Soc. 2017, 139 (35), 12251-12258. https://doi.org/10.1021/jacs.7b05899.

(18) Matsui, J. K.; Primer, D. N.; Molander, G. A. Metal-Free C-H Alkylation of Heteroarenes with Alkyltrifluoroborates: A General Protocol for $1^{\circ}, 2^{\circ}$ and $3^{\circ}$ Alkylation. Chem. Sci. 2017, 8 (5), 3512-3522. https://doi.org/10.1039/c7sc00283a.

(19) Bieszczad, B.; Perego, L. A.; Melchiorre, P. Photochemical C-H Hydroxyalkylation of Quinolines and Isoquinolines. Angew. Chemie - Int. Ed. 2019, 58 (47), 16878-16883. https://doi.org/10.1002/anie.201910641.

(20) McCallum, T.; Pitre, S. P.; Morin, M.; Scaiano, J. C.; Barriault, L. The Photochemical Alkylation and Reduction of Heteroarenes. Chem. Sci. 2017, 8 (11), 7412-7418. https://doi.org/10.1039/c7sc03768f. 
(21) Huang, C. Y.; Li, J.; Liu, W.; Li, C. J. Diacetyl as a "Traceless" Visible Light Photosensitizer in Metal-Free Cross-Dehydrogenative Coupling Reactions. Chem. Sci. 2019, 10 (19), 5018-5024. https://doi.org/10.1039/c8sc05631e.

(22) Wang, H.; Gao, X.; Lv, Z.; Abdelilah, T.; Lei, A. Recent Advances in Oxidative R1-H/R2H Cross-Coupling with Hydrogen Evolution via Photo-/Electrochemistry. Chem. Rev. 2019, 119 (12), 6769-6787. https://doi.org/10.1021/acs.chemrev.9b00045.

(23) Chernyak, N.; Dudnik, A. S.; Huang, C.; Gevorgyan, V. PyDipSi: A General and Easily Modifiable/Traceless Si-Tethered Directing Group for C-H Acyloxylation of Arenes. J. Am. Chem. Soc. 2010, 132 (24), 8270-8272. https://doi.org/10.1021/ja1033167.

(24) Parasram, M.; Gevorgyan, V. Silicon-Tethered Strategies for C-H Functionalization Reactions. Acc. Chem. Res. 2017, 50 (8), 2038-2053. https://doi.org/10.1021/acs.accounts.7b00306.

(25) Bürger, H. Organosilicon Chemistry. Angew. Chemie Int. Ed. English 1969, 8(7), 526528. https://doi.org/10.1002/anie.196905261.

(26) Rand, A. W.; Montgomery, J. Catalytic Reduction of Aryl Trialkylammonium Salts to Aryl Silanes and Arenes. Chem. Sci. 2019, 10 (20), 5338-5344. https://doi.org/10.1039/c9sc01083a.

(27) Itami, K.; Mitsudo, K.; Yoshida, J. i. A Pyridylsilyl Group Expands the Scope of Catalytic 
Intermolecular Pauson-Khand Reactions. Angew. Chem., Int. Ed.2002,41, 3481-3484.

(28) Itami, K.; Mitsudo, K.; Kamei, T.; Koike, T.; Nokami, T.; Yoshida, J. I. Highly Efficient Carbopalladation across Vinylsilane: Dual Role of the 2-PyMe2Si Group as a Directing Group and as a Phase Tag. J. Am. Chem. Soc. 2000, 122 (48), 12013-12014. https://doi.org/10.1021/ja002582q.

(29) Xu, Z.; Chai, L.; Liu, Z. Q. Free-Radical-Promoted Site-Selective C-H Silylation of Arenes by Using Hydrosilanes. Org. Lett. 2017, 19 (20), 5573-5576. https://doi.org/10.1021/acs.orglett.7b02717.

(30) Toutov, A. A.; Liu, W. B.; Betz, K. N.; Fedorov, A.; Stoltz, B. M.; Grubbs, R. H. Silylation of C-H Bonds in Aromatic Heterocycles by an Earth-Abundant Metal Catalyst. Nature 2015, 518 (7537), 80-84. https://doi.org/10.1038/nature14126.

(31) Xu, N. X.; Li, B. X.; Wang, C.; Uchiyama, M. Sila- and Germacarboxylic Acids: Precursors for the Corresponding Silyl and Germyl Radicals. Angew. Chemie - Int. Ed. 2020, 59(26), 10639-10644. https://doi.org/10.1002/anie.202003070.

(32) Liu, W.-B.; Schuman, D. P.; Yang, Y.-F.; Toutov, A. A.; Liang, Y.;Klare, H. F. T.; Nesnas, N.; Oestreich, M.; Blackmond, D. G.; Virgil, S.C.; Banerjee, S.; Zare, R. N.; Grubbs, R. H.; Houk, K. N.; Stoltz, B. M.. Potassium Tert-Butoxide-Catalyzed Dehydrogenative CH Silylation of Heteroaromatics: A Combined Experimental and Computational Mechanistic Study. J. Am. Chem. Soc. 2017, 139 (20), 6867-6879. 
https://doi.org/10.1021/jacs.6b13031.

(33) Richter, S. C.; Oestreich, M. Emerging Strategies for C-H Silylation. Trends Chem. 2020, 2(1), 13-27. https://doi.org/10.1016/j.trechm.2019.07.003.

(34) Liu, S.; Pan, P.; Fan, H.; Li, H.; Wang, W.; Zhang, Y. Photocatalytic C-H Silylation of Heteroarenes by Using Trialkylhydrosilanes. Chem. Sci. 2019, 10 (13), 3817-3825. https://doi.org/10.1039/c9sc00046a.

(35) Buratti, W.; Gardini, G. P.; Minisci, F.; Bertini, F.; Galli, R.; Perchinunno, M. Nucleophilic Character of Alkyl Radicals-V. Tetrahedron 1971, 27 (15), 3655-3668. https://doi.org/10.1016/s0040-4020(01)97776-2.

(36) Katz, R. B.; Mistry, J.; Mitchell, M. B. An Improved Method for the MonoHydroxymethylation of Pyridines. a Modification of the Minisci Procedure. Synth. Commun. 1989, 19(1-2), 317-325. https://doi.org/10.1080/00397918908050984.

(37) Liu, W.; Yang, X.; Zhou, Z. Z.; Li, C. J. Simple and Clean Photo-Induced Methylation of Heteroarenes with MeOH. Chem 2017, 2 (5), 688-702. https://doi.org/10.1016/j.chempr.2017.03.009.

(38) Jin, J.; MacMillan, D. W. C. Alcohols as Alkylating Agents in Heteroarene C-H Functionalization. Nature 2015, 525(7567), 87-90. https://doi.org/10.1038/nature14885.

(39) Huff, C. A.; Cohen, R. D.; Dykstra, K. D.; Streckfuss, E.; DiRocco, D. A.; Krska, S. W. 
Photoredox-Catalyzed Hydroxymethylation of Heteroaromatic Bases. J. Org. Chem. 2016, 81 (16), 6980-6987. https://doi.org/10.1021/acs.joc.6b00811.

(40) He, F. S.; Ye, S.; Wu, J. Recent Advances in Pyridinium Salts as Radical Reservoirs in $\begin{array}{llllll}\text { Organic Synthesis. ACS } & \text { Catal. 2019, } 9 & \text { (10), 8943-8960. }\end{array}$ https://doi.org/10.1021/acscatal.9b03084.

(41) Togni, A.; Rössler, S. L.; Jelier, B. J.; Magnier, E.; Dagousset, G.; Carreira, E. M. Pyridinium Salts as Redox-Active Functional Group Transfer Reagents. Angew. Chemie Int. Ed. 2019, 2-19. https://doi.org/10.1002/anie.201911660.

(42) Buquoi, J. Q.; Lear, J. M.; Gu, X.; Nagib, D. A. Heteroarene Phosphinylalkylation via a Catalytic, Polarity-Reversing Radical Cascade. ACS Catal. 2019, 9 (6), 5330-5335. https://doi.org/10.1021/acscatal.9b01580.

(43) Rammal, F.; Gao, D.; Boujnah, S.; Gaumont, A.-C.; Hussein, A. A.; Lakhdar, S. VisibleLight-Mediated C-H Alkylation of Pyridine Derivatives. Org. Lett. 2020. https://doi.org/10.1021/acs.orglett.0c02863.

(44) Ma, X.; Dang, H.; Rose, J. A.; Rablen, P.; Herzon, S. B. Hydroheteroarylation of Unactivated Alkenes Using N-Methoxyheteroarenium Salts. J. Am. Chem. Soc. 2017, 139 (16), 5998-6007. https://doi.org/10.1021/jacs.7b02388.

(45) Capaldo, L.; Ravelli, D. Alkoxy Radicals Generation: Facile Photocatalytic Reduction of: 
N -Alkoxyazinium or Azolium Salts. Chem. Commun. 2019, 55 (21), 3029-3032. https://doi.org/10.1039/c9cc00035f.

(46) Inial, A.; Morlet-Savary, F.; Lalevée, J.; Gaumont, A. C.; Lakhdar, S.; Lakhdar, S. VisibleLight-Mediated Access to Phosphate Esters. Org. Lett. 2020, 22 (11), 4404-4407. https://doi.org/10.1021/acs.orglett.0c01409.

(47) Quint, V.; Morlet-Savary, F.; Lohier, J. F.; Lalevée, J.; Gaumont, A. C.; Lakhdar, S. MetalFree, Visible Light-Photocatalyzed Synthesis of Benzo[b]Phosphole Oxides: Synthetic and Mechanistic Investigations. J. Am. Chem. Soc. 2016, 138 (23), 7436-7441. https://doi.org/10.1021/jacs.6b04069.

(48) Capaldo, L.; Quadri, L. L.; Ravelli, D. Photocatalytic Hydrogen Atom Transfer: The Philosopher's Stone for Late-Stage Functionalization? Green Chem. 2020, $22(11), 3376-$ 3396. https://doi.org/10.1039/d0gc01035a.

(49) Kim, K.; Choi, H.; Kang, D.; Hong, S. Visible-Light Excitation of QuinolinoneContaining Substrates Enables Divergent Radical Cyclizations. Org. Lett. 2019, 21 (9), 3417-3421. https://doi.org/10.1021/acs.orglett.9b01155.

(50) Jeon, J.; He, Y. T.; Shin, S.; Hong, S. Visible-Light-Induced Ortho-Selective Migration on Pyridyl Ring: Trifluoromethylative Pyridylation of Unactivated Alkenes. Angew. Chemie - Int. Ed. 2020, 59(1), 281-285. https://doi.org/10.1002/anie.201912746. 
(51) Jung, S.; Lee, H.; Moon, Y.; Jung, H. Y.; Hong, S. Site-Selective c-h Acylation of Pyridinium Derivatives by Photoredox Catalysis. ACS Catal. 2019, 9 (11), 9891-9896. https://doi.org/10.1021/acscatal.9b03367.

(52) He, Y. T.; Kang, D.; Kim, I.; Hong, S. Metal-Free Photocatalytic Trifluoromethylative Pyridylation of Unactivated Alkenes. Green Chem. 2018, 20 (22), 5209-5214. https://doi.org/10.1039/c8gc02782j.

(53) Kim, Y.; Lee, K.; Mathi, G. R.; Kim, I.; Hong, S. Visible-Light-Induced Cascade Radical Ring-Closure and Pyridylation for the Synthesis of Tetrahydrofurans. Green Chem. 2019, 21 (8), 2082-2087. https://doi.org/10.1039/c9gc00414a.

(54) Kim, I.; Park, B.; Kang, G.; Kim, J.; Jung, H.; Lee, H.; Baik, M. H.; Hong, S. Visible-LightInduced Pyridylation of Remote $\mathrm{C}(\mathrm{Sp} 3)-\mathrm{H}$ Bonds by Radical Translocation of NAlkoxypyridinium Salts. Angew. Chemie - Int. Ed. 2018, 57 (47), 15517-15522. https://doi.org/10.1002/anie.201809879.

(55) Kim, I.; Kang, G.; Lee, K.; Park, B.; Kang, D.; Jung, H.; He, Y. T.; Baik, M. H.; Hong, S. Site-Selective Functionalization of Pyridinium Derivatives via Visible-Light-Driven Photocatalysis with Quinolinone. J. Am. Chem. Soc. 2019, 141 (23), 9239-9248. https://doi.org/10.1021/jacs.9b02013.

(56) Mathi, G. R.; Jeong, Y.; Moon, Y.; Hong, S. Photochemical Carbopyridylation of Alkenes Using N-Alkenoxypyridinium Salts as Bifunctional Reagents. Angew. Chemie - Int. Ed. 
2020, 59(5), 2049-2054. https://doi.org/10.1002/anie.201913320.

(57) Niu, L.; Liu, J.; Liang, X. A.; Wang, S.; Lei, A. Visible Light-Induced Direct $\alpha$ C-H Functionalization of Alcohols. Nat. Commun. 2019, 10 (1), 1-7. https://doi.org/10.1038/s41467-019-08413-9.

(58) Barthelemy, A. L.; Tuccio, B.; Magnier, E.; Dagousset, G. Alkoxyl Radicals Generated under Photoredox Catalysis: A Strategy for Anti-Markovnikov Alkoxylation Reactions. Angew. Chemie - Int. Ed. 2018, $57 \quad$ (42), 13790-13794. https://doi.org/10.1002/anie.201806522.

(59) Barthelemy, A. L.; Tuccio, B.; Magnier, E.; Dagousset, G. Intermolecular Trapping of Alkoxyl Radicals with Alkenes: A New Route to Ether Synthesis. Synlett 2019, 30 (13), 1489-1495. https://doi.org/10.1055/s-0037-1611785.

(60) Deletraz, A.; Zéamari, K.; Di Meo, F.; Fabre, P. L.; Reybier, K.; Trouillas, P.; Tuccio, B.; Durand, G. Reactivities of MeO-Substituted PBN-Type Nitrones. New J. Chem. 2019, 43 (39), 15754-15762. https://doi.org/10.1039/c9nj03805a.

(61) Lalevée, J.; Blanchard, N.; Ei-Roz, M.; Graff, B.; Allonas, X.; Fouassier, J. P. New Photoinitiators Based on the Silyl Radical Chemistry: Polymerization Ability, ESR Spin Trapping, and Laser Flash Photolysis Investigation. Macromolecules 2008, 41 (12), 4180-4186. https://doi.org/10.1021/ma8005125. 
(62) Shukla, D.; Ahearn, W. G.; Farid, S. Chain Amplification in Photoreactions of NAlkoxypyridinium Salts with Alcohols: Mechanism and Kinetics. J. Org. Chem. 2005, 70 (17), 6809-6819. https://doi.org/10.1021/jo050726j.

(63) Shukla, D.; Adiga, S. P.; Ahearn, W. G.; Dinnocenzo, J. P.; Farid, S. Chain-Amplified Photochemical Fragmentation of N-Alkoxypyridinium Salts: Proposed Reaction of Alkoxyl Radicals with Pyridine Bases to Give Pyridinyl Radicals. J. Org. Chem. 2013, 78 (5), 1955-1964. https://doi.org/10.1021/jo301975j.

(64) Shukla, D.; Young, R. H.; Farid, S. Reducing Power of Photogenerated $\alpha$-Hydroxy Radicals. Proton-Coupled Electron Transfer. J. Phys. Chem. A 2004, 108 (47), 1038610394. https://doi.org/10.1021/jp0466340. 